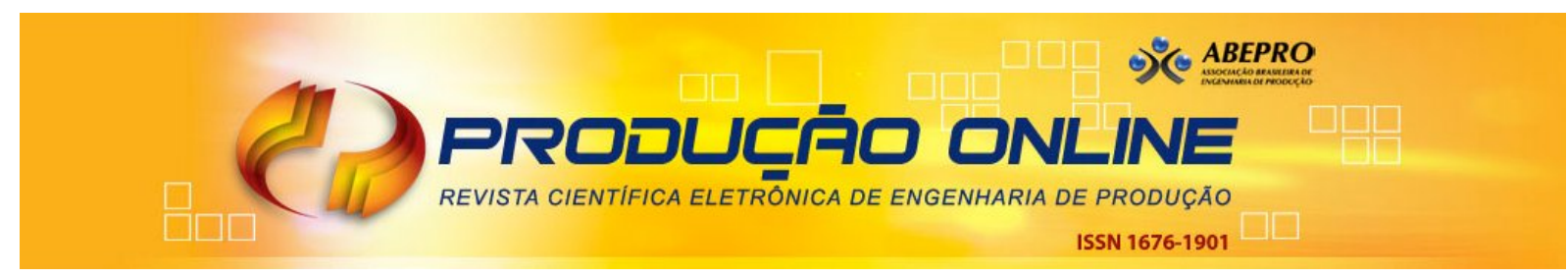

\title{
O QUE FAVORECE A RESILIÊNCIA NA CADEIA DE SUPRIMENTOS? INSIGHTS A PARTIR DE UMA REVISÃO SISTEMÁTICA DE LITERATURA
}

\section{WHAT PROMOTES THE SUPPLY CHAIN RESILIENCE? INSIGHTS FROM A SYSTEMATIC LITERATURE REVIEW}

\author{
Flávio Henrique de Oliveira Costa* E-mail: flaviocosta@dep.ufscar.br \\ Andrea Lago da Silva* E-mail: deialago@ufscar.br \\ Carla Roberta Pereira** E-mail: carla.pereira@udesc.br \\ *Universidade Federal de São Carlos (UFSCar), São Carlos, SP \\ **Universidade do Estado de Santa Catarina (UDESC), Joinville, SC
}

\begin{abstract}
Resumo: Riscos e vulnerabilidades são fatores intrínsecos a qualquer cadeia de suprimentos. Para superar possíveis problemas gerados por rupturas no fluxo de materiais ao longo das cadeias, gestores e pesquisadores estão cada vez mais interessados em explorar fatores internos e externos que auxiliam a geração de resiliência. Nesse contexto, o objetivo deste estudo foi caracterizar os facilitadores à resiliência na cadeia de suprimentos presentes na literatura e analisar suas possíveis inter-relações. Para tanto, utilizou-se como método de pesquisa uma revisão sistemática de literatura. Como resultado, doze facilitadores foram caracterizados e relacionados, formando três grandes grupos: um relacionado ao capital social e ao conhecimento, outro a resposta à ruptura, e um último agrupamento ligado ao relacionamento e a preparação para rupturas. Trabalhos futuros devem buscar responder empiricamente como os facilitadores mapeados contribuem para a geração de resiliência, fazendo uso de casos críticos nacionais como mercados de produtos de alta variabilidade ou perecíveis.
\end{abstract}

Palavras-chave: Facilitadores. Gestão da Cadeia de Suprimentos. Resiliência, Revisão Sistemática da Literatura.

Abstract: Risks and vulnerabilities are intrinsic factors for any supply chain. To overcome possible problems caused by disruptions to material flow in supply chains, managers and researchers are increasingly interested in exploring internal and external factors that help generate resilience. In this context, the aim of this study was to characterize the enablers to resilience in supply chains in the literature and analyze their possible interrelationships. To do so, a systematic literature review was conducted as a research method. As a result, twelve enablers were characterized and related, forming three groups: one related to share capital and knowledge; another concerning the response to rupture; and the third group linked to the relationship and preparation regarding ruptures. Future work should seek to answer empirically how the enablers contribute to generating resilience, making use of national critical cases as high variability or perishable markets.

Keywords: Enablers. Supply Chain Management. Resilience. Systematic Literature Review.

\section{INTRODUÇÃO}

A resiliência na cadeia de suprimentos é definida por Ponomarov e Holcomb (2009) como a capacidade adaptativa de uma cadeia em se preparar para eventos inesperados, responder a rupturas no fluxo de bens e se recuperar delas, mantendo continuidade das operações a um nível desejado de conectividade e controle de 
estruturas e funções organizacionais. Tanto rupturas internas quanto externas às empresas possuem a capacidade de impactar negativamente diversas operações organizacionais. Isso prejudica a cadeia de suprimentos em sua missão principal que é a de entregar produtos e/ou serviços nos locais, nas quantidades, no tempo e nos custos adequados (SVENSSON, 2003; BLACKHURST; DUNN; CRAIGHEAD, 2011; CARVALHO et al., 2012).

Vários são os exemplos de rupturas e de seus respectivos impactos em empresas e cadeias de suprimentos. Em julho de 2007, um terremoto de magnitude 6.8 ocorrido no Japão causou destruição na região onde estavam localizados fornecedores-chave da Toyota. A Toyota Company teve que interromper a produção em 12 plantas por falta de suprimentos, uma vez que trabalhava com o sistema justin-time e possuía uma base menor de fornecimento. Como resultado, a empresa atrasou a produção e a entrega de 55.000 carros, o que ocasionou grandes prejuízos para si e para toda a cadeia (SHEFFI; RICE, 2005; PETTIT; FIKSEL; CROXTON, 2010). No Brasil, protestos contra o governo em 2013 prejudicaram empresas ao bloquear importantes rodovias, afetando a Logística de distribuidoras de combustível e dos Correios (ILOS, 2013). Em fevereiro de 2015, uma greve de caminhoneiros causou o bloqueio de aproximadamente 115 pontos em quase 70 rodovias. Esses bloqueios chegaram a parar uma montadora de automóveis, além de afetar frigoríficos e laticínios. A grande problemática é que empresas que mantinham apenas estoques mínimos foram obrigadas a parar parcialmente ou completamente suas plantas (ALMEIDA, 2015; PUPO; LAGUNA; BRUNO, 2013; VALOR ECONÔMICO, 2015).

Mccormack, Bronzo e Oliveira (2002) destacam a atual tendência de as empresas adotarem os sistemas de produção enxuta, evitando a superprodução de itens sem demanda confirmada, consequente, altos estoques dentro da empresa e entre pontos da cadeia. Apesar da grande economia na cadeia, tal ação pode gerar perdas maiores por falta de recursos emergenciais caso a empresa não seja capaz de tomar decisões rápidas. Estudos sobre resiliência na cadeia de suprimentos surgem da necessidade do desenvolvimento de processos e de procedimentos seguros e maleáveis o bastante para responder a rupturas inesperadas (RICE; CANIATO, 2003). Nesse quesito, o gerenciamento dos riscos busca formas de mitigar incertezas previsíveis, porém não garante formas de recuperação a eventos inesperados de rupturas. Em contrapartida, a resiliência, além de proporcionar a preparação para as incertezas devido aos processos de gestão de riscos inclusos, busca a recuperação das organizações por meio de ações alternativas e complementares (JÜTTNER; MAKLAN, 2011). Autores como Ponomarov e Holcomb (2009), Blackhurst, Dunn e Craighead (2011), Scholten, Scott e Fynes (2014), Pereira e Silva (2015) e Kamalahmadi e Parast (2016) consideram que os estudos sobre a resiliência na cadeia de suprimentos ainda se encontram em fase de crescimento.

No que se refere à resiliência na cadeia de suprimentos e seus facilitadores, Pettit, Fiksel e Croxton (2010) sugerem que estudos definam melhor os facilitadores, 
focando questões como flexibilidade e adaptabilidade. O objetivo deste artigo é, portanto, caracterizar os facilitadores à resiliência na cadeia de suprimentos, considerando autores presentes na literatura entre 2000 e janeiro de 2015 e analisar suas possíveis inter-relações. Para isso, uma revisão sistemática da literatura e uma análise crítica foram realizadas como forma de se sistematizar tais facilitadores. Este trabalho pretende contribuir para o conhecimento na área, definindo um conjunto de facilitadores para empresas que pretendam construir práticas de gestão de cadeias de suprimentos resiliente.

Considerando os diversos termos utilizados pela literatura para conceituar resiliência na cadeia de suprimentos, o termo "facilitador" neste estudo englobará tanto atividades, quanto procedimentos, responsabilidades, ferramentas, práticas e técnicas que estejam relacionadas a qualquer etapa do processo de construção de resiliência na cadeia de suprimentos. Destaca-se que a consideração de tal definição se deu em função da intenção de se caracterizar esses facilitadores de forma ampla, considerando pontos a exemplo das capabilities utilizadas por Pettit, Fiksel e Croxton (2010) e dos factors pesquisados por Ambulkar, Blackhurst e Grawe (2015).

O artigo se organiza da seguinte forma: na seção 2, será apresentado o termo resiliência em cadeias de suprimentos, bem como uma breve discussão a respeito dela; a seção 3 apresentará os procedimentos metodológicos utilizados para a realização da revisão (3.1) e para a análise de conteúdo dos artigos (3.2). Já a seção 4 apresentará os facilitadores à resiliência na cadeia de suprimentos (4.1) e as análises realizadas (4.2). Por fim, a seção 5 apresentará conclusões, limitações e implicações teóricas e gerenciais dessa pesquisa.

\section{TERMO RESILIÊNCIA NA CADEIA DE SUPRIMENTOS}

As cadeias de suprimentos têm expandido suas conexões para se tornarem globais, porém tornam-se mais complexas, como consequência. A preocupação com os resultados negativos das rupturas nas cadeias de suprimentos também tem se tornado mais perceptível e gerado impactos maiores às organizações (BLACKHURST; DUNN; CRAIGHEAD, 2011). Bueno-Solano e Cedillo-Campos (2014) concluem que após uma ruptura catastrófica, como os atentados de 11 de setembro nos Estados Unidos, os custos de uma cadeia de suprimentos podem saltar de 6,6 para até 31,29 milhões de dólares. Nota-se, portanto, uma correlação direta entre o nível de resiliência da cadeia de suprimentos e os impactos econômicos gerados pelas rupturas. Esse valor demonstra como é significativo o impacto desse tipo de ruptura em uma empresa.

Para Christopher e Peck (2004), a resiliência na cadeia é definida como a capacidade de um sistema em reestabelecer o seu desempenho normal ou ainda alcançar um desempenho superior, após um dado rompimento no fluxo. Já para Jüttner e Maklan (2011), a resiliência na cadeia de suprimentos permite que se reduzam as consequências negativas dos eventos, facilitando uma rápida 
recuperação da cadeia de suprimentos ao seu estado original ou melhorado, e também reduzindo as vulnerabilidades nos casos de riscos evidentes.

Para uma melhor compreensão do processo de respostas a rupturas, Scholten, Scott e Fynes (2014) classificaram as fases da resiliência de acordo com a Figura 1.

Figura 1 - Fases do gerenciamento de rupturas

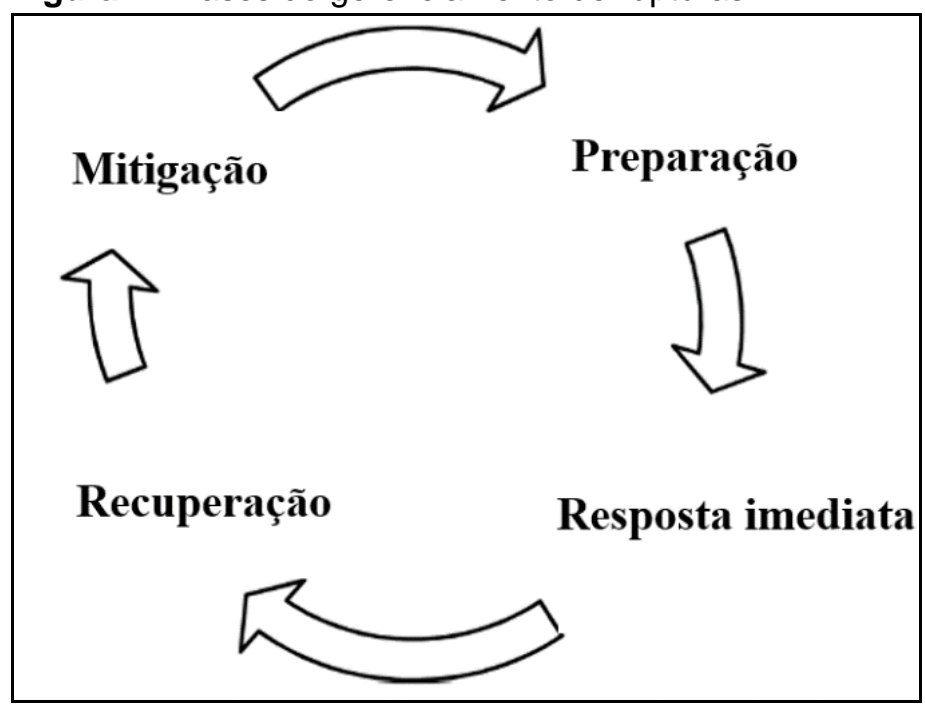

Fonte: Adaptado de Scholten, Scott e Fynes (2014)

De acordo com Sheffi e Rice (2005) e Scholten, Scott e Fynes (2014), podese observar que a preparação para a ruptura ocorre quando a empresa possui algum tipo de prevenção para dado evento, minimizando assim seus efeitos - por exemplo, planos de contingência. A resposta imediata consiste nas ações tomadas após a ruptura, enquanto que a recuperação consiste na implementação destas ações para obtenção do estado desejado. Para Scholten, Scott e Fynes (2014), a fase de mitigação consiste na gestão de riscos e na melhoria contínua dos processos à resiliência; ou seja, nessa fase a empresa/cadeia desenvolve ou aperfeiçoa seus processos no sentido de aumentar a resiliência.

Os riscos de rupturas, por sua vez, podem surgir de diversos pontos. Por isso, Stecke e Kumar (2009) citam e classificam alguns desses riscos a rupturas causadas por eventos inesperados, como pode ser observado no Quadro 1. Os autores analisam ainda a severidade e a possibilidade de ocorrência de cada uma dessas catástrofes. Entretanto, estas catástrofes não são homogêneas e, novos problemas, ou outros impactos e probabilidades, podem ser localizados a depender da empresa ou do setor estudado. Como percebido por Silvestre (2015), em seu estudo sobre uma cadeia petroleira brasileira, há ainda algumas barreiras distintas, como corrupção, pressões sociais, falta de transparência e elevado grau de complexidade. Em uma pesquisa realizada no Brasil por Oliveira et al. (2015), outros riscos são destacados, como o aumento da temperatura e o risco de contaminação de insumos. 
Quadro 1 - Tipos de rupturas

\begin{tabular}{|c|c|}
\hline Classificações & Riscos \\
\hline \multirow[t]{8}{*}{ Ataques terroristas } & Ataques à infraestrutura \\
\hline & Violência \\
\hline & Assassinato em massa \\
\hline & $\begin{array}{l}\text { Ataques nucleares, químicos } \\
\text { ou biológicos }\end{array}$ \\
\hline & $\begin{array}{l}\text { Ameaças e propagandas } \\
\text { para aterrorizar }\end{array}$ \\
\hline & Assassinato de político(s) \\
\hline & $\begin{array}{l}\text { Sabotagem de meios de } \\
\text { transporte }\end{array}$ \\
\hline & Ciberterrorismo \\
\hline \multirow[t]{6}{*}{ Questões naturais } & Desastres naturais \\
\hline & Destruição de infraestrutura \\
\hline & Ruptura de transporte \\
\hline & Perigos à saúde \\
\hline & Extremos climáticos \\
\hline & $\begin{array}{l}\text { Fogo natural (erupções e } \\
\text { incêndios florestais) }\end{array}$ \\
\hline \multirow[t]{2}{*}{ Acidentes } & Acidentes de transporte \\
\hline & Acidentes industriais \\
\hline \multirow{2}{*}{$\begin{array}{l}\text { Problemas sociais e } \\
\text { ambientais }\end{array}$} & Greves \\
\hline & $\begin{array}{l}\text { Problemas ambientais } \\
\text { (mudanças nos gastos do } \\
\text { governo, no estilo de vida e } \\
\text { na tecnologia da manufatura) }\end{array}$ \\
\hline
\end{tabular}

Fonte: Adaptado de Stecke e Kumar (2009)

Mediante eventos de diferentes probabilidades e impactos, há aqueles de alto impacto e que, normalmente, possuem baixa probabilidade de ocorrência; ou seja, dificilmente podem ser previstos, como o caso de ataques terroristas. A Figura 2 demonstra alguns exemplos de rupturas e seus impactos. Para as rupturas de baixo impacto e alta previsibilidade, o gerenciamento de riscos é efetivo para a solução, porém, para rupturas de alto impacto e baixa previsibilidade é necessário o desenvolvimento de resiliência (AMBULKAR; BLACKHURST; GRAWE, 2015). 
Figura 2 - Rupturas e seus impactos

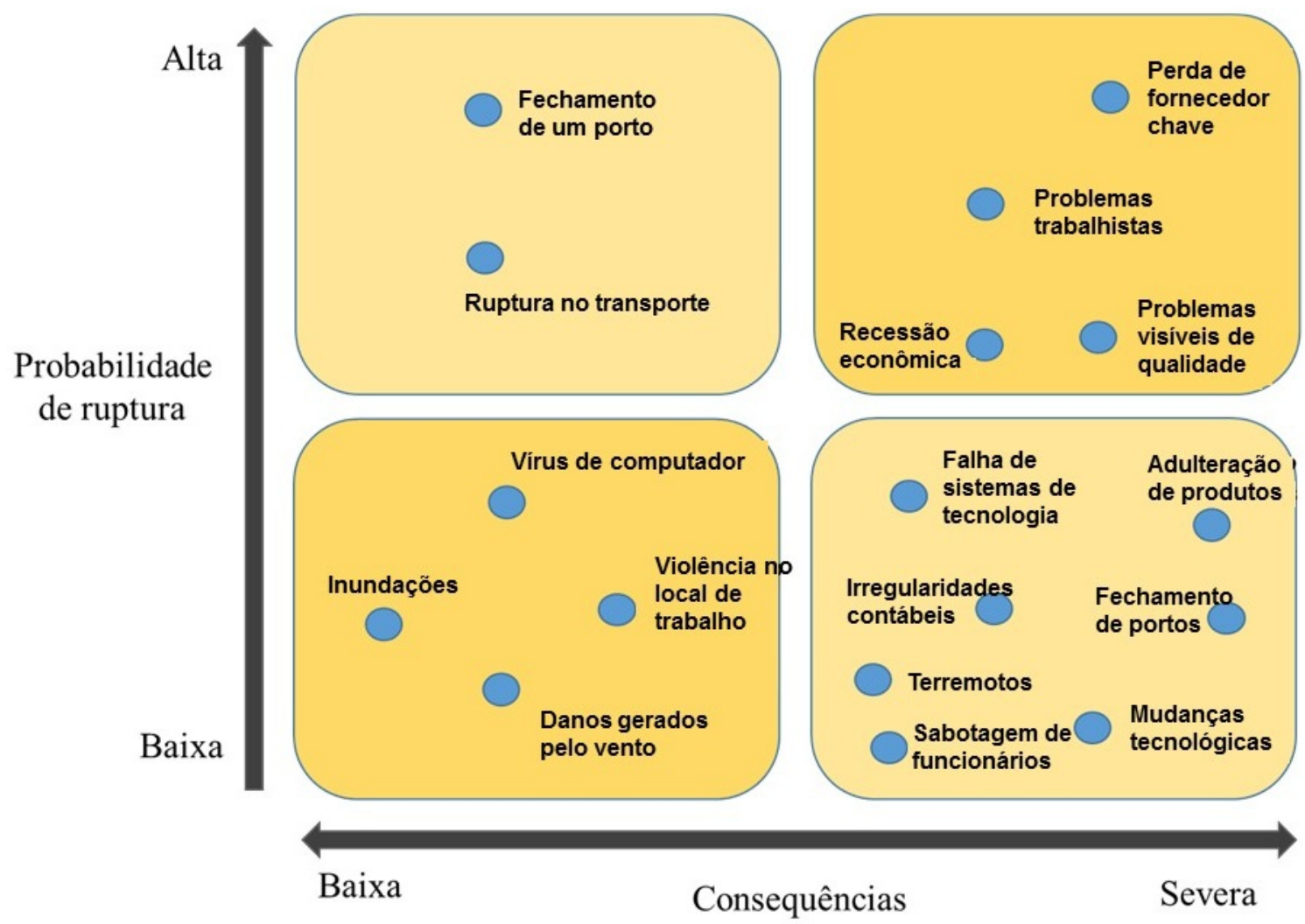

Fonte: Adaptado de Adaptado de Sheffi e Rice (2005)

O tema resiliência na cadeia de suprimentos vem crescendo na literatura (KAMALAHMADI; PARAST, 2016). Nos últimos anos, autores avançaram em relação à definição de facilitadores que contribuem para a geração de resiliência na cadeia de suprimentos. São exemplos disso os trabalhos de Ambulkar, Blackhurst e Grawe (2015) ao explorarem os facilitadores que contribuem à resiliência em diferentes eventos geradores de ruptura, e de Pereira, Christopher e Silva (2014) que buscaram compreender o papel da função Compras na geração de resiliência na cadeia de suprimentos. Uma das sugestões para pesquisa futura desses autores é a oportunidade de desenvolver conhecimentos a respeito dos facilitadores e das barreiras à resiliência. Ainda nesse sentido, o trabalho de Scholten, Scott e Fynes (2014) analisou a teoria e a prática para o desenvolvimento de uma cadeia de suprimentos resiliente e identificou as melhores práticas em gerenciamento de desastres. Hohenstein et al. (2015), em contrapartida, executaram uma revisão sistemática a respeito da resiliência na cadeia de suprimentos, classificando a resiliência e seus elementos em proativos ou reativos e construindo um framework para a resiliência. Observa-se assim muitos avanços nesta temática, estendendo conhecimento em vários segmentos de estudo. 


\section{PROCEDIMENTOS METODOLÓGICOS}

Esta seção apresenta os procedimentos metodológicos utilizados na realização da presente pesquisa. Inicialmente, foi realizada uma revisão sistemática da literatura e, posteriormente, os trabalhos resultantes dessa revisão foram submetidos a uma análise de conteúdo e uma análise crítica de forma a extrair informações.

\subsection{Revisão Sistemática de Literatura}

Este trabalho se iniciou com uma revisão de escopo, que teve o objetivo de definir o problema de pesquisa, formar objetivos mais claros e gerar as hipóteses de pesquisa. Durante a revisão de escopo, selecionaram-se também as palavraschaves mais amplamente utilizadas nos textos para posteriormente utilizá-las nas strings da revisão sistemática (BADGER et al., 2010; JESSON; MATHESON; LACEY, 2011; COLICCHIA; STROZZI, 2012).

Após a realização da revisão de escopo, iniciou-se a revisão sistemática deste trabalho, que teve como objetivo responder duas questões de revisão:

Q1) Quais os facilitadores à geração da resiliência na cadeia de suprimentos?

Q2) Qual a interconexão entre tais facilitadores?

A execução de uma revisão sistemática da literatura foi desenvolvida, seguindo a linha de Colicchia e Strozzi (2012), Thomé et al. (2012), Barreto e Amaral (2013) e Pereira, Christopher e Silva (2014). Esses autores consideram que essa técnica de revisão, além de ser uma forma de obter maior rigor e melhores níveis de confiabilidade, permite encontrar lacunas na teoria a serem exploradas. Tal método evita também vieses possivelmente gerados com a seleção de artigos (DEYNER; TRANFIELD, 2009; JESSON; MATHESON; LACEY, 2011). A opção pela utilização desse método leva em conta a intenção de identificar o maior número possível de facilitadores, de forma sistemática, em meio a grande gama de trabalhos publicados na área de Gestão de Operações.

Para a realização dessa revisão, foram seguidas as etapas definidas por Tranfield, Denyer e Smart (2003) partindo da leitura de escopo. No estabelecimento de strings foi necessária a prévia definição de quais questões seriam respondidas (destacadas previamente). Por meio do protocolo, é possível visualizar as principais etapas da revisão sistemática realizada apresentadas no Quadro 2. 
Quadro 2 - Protocolo da revisão sistemática

\begin{tabular}{lll}
\hline \multicolumn{1}{c}{ Estágio } & \multicolumn{1}{c}{ Obtenção } & \multicolumn{1}{c}{ Detalhes } \\
\hline $\begin{array}{l}\text { Leitura de } \\
\text { Escopo }\end{array}$ & $\begin{array}{l}\text { Busca nos principais periódicos na } \\
\text { área de SCM e Operações citados em } \\
\text { trabalhos no tema e indicação de } \\
\text { especialistas. }\end{array}$ & $\begin{array}{l}\text { * Definir o problema de pesquisa. } \\
\text { * Identificar constructos. } \\
\text { * Encontrar palavras chave (para strings). }\end{array}$ \\
\hline $\begin{array}{ll}\text { Condução da } \\
\text { Revisão }\end{array}$ & $\begin{array}{ll}\text { Buscas nas bases de dados: Scopus, } \\
\text { ISI Web of Science, Proquest e Scielo. }\end{array}$ & $\begin{array}{l}\text { 20 }^{\circ} \text { Filtro: leitura do título e abstract. } \\
\text { Analisar acesso e qualidade do periódico. } \\
3^{\circ} \text { Filtro/Classificação: Leitura completa e avaliação } \\
\text { da qualidade do artigo (leitura critica). }\end{array}$ \\
\hline $\begin{array}{l}\text { Análise de } \\
\text { dados }\end{array}$ & Leitura dos artigos selecionados & Ler e analisar o material selecionado. \\
\hline
\end{tabular}

Fonte: Autores

Para dar início à busca nas bases de dados, o primeiro passo foi a construção de strings de busca. Para a criação destas, utilizaram-se dicionários, thesaurus e revisão de nativo na língua inglesa com experiência na temática. A string utilizada foi ("supply chain*") NEAR/5 (resilien*) e foi construída de acordo com as bases a serem utilizadas de forma a considerar os constructos necessários. Foram selecionadas também as áreas a serem buscadas na pesquisa, novamente de acordo com o permitido por cada base, de forma a priorizar artigos nas áreas de Ciências Físicas, Engenharias, Ciências Sociais e Humanas, excluindo os artigos referentes a Ciências da Vida e Saúde.

As bases de dados foram selecionadas a partir das bases mais amplamente utilizadas na edição especial da revista Supply Chain Management: an International Journal (vol.19, n.5/6) que se concentrou em artigos que se utilizaram do método de revisão sistemática. Dentre essas, optou-se pela seleção das bases que retornaram maior número de resultados para a string a ser utilizada nesse trabalho - Proquest, ISI Web of Science e Scopus. Optou-se também pela seleção de uma base com artigos nacionais - Scielo. As pesquisas em tais bases de dados foram realizadas em janeiro de 2015 e considerou-se um período de 15 anos, considerado o ano de 2000 o início de publicação no tema (HOHENSTEIN et al., 2015; KAMALAHMADI; PARAST, 2016). Para a seleção dos artigos aplicaram-se alguns filtros conforme destacados no Quadro 2. No $2^{\circ}$ Filtro realizou-se a leitura da Introdução e da Conclusão e os filtros utilizados foram: acesso, qualidade, temática, unidade de análise e definição dos facilitadores à resiliência descritos, os quais podem ser observados no Quadro 3. Ao término da seleção dos artigos, executou-se uma leitura crítica dos artigos (WALLACE; WRAY, 2011). 
Quadro 3 - Critérios de inclusão e exclusão

\begin{tabular}{|c|c|c|c|c|}
\hline Filtro & Critério & Inclusão & Exclusão & $\begin{array}{l}\text { Tipo de } \\
\text { leitura }\end{array}$ \\
\hline \multirow[t]{2}{*}{1} & Foco & $\begin{array}{l}\text { Tratar de resiliência em } \\
\text { SCM ou gestão de } \\
\text { operações. }\end{array}$ & $\begin{array}{l}\text { Se referir a resiliência com } \\
\text { enfoque em outra área que não } \\
\text { em cadeia de suprimentos e } \\
\text { gestão de operações. }\end{array}$ & \multirow[t]{2}{*}{$\begin{array}{l}\text { Leitura do } \\
\text { título e } \\
\text { abstract. }\end{array}$} \\
\hline & Resiliência & $\begin{array}{l}\text { Tratar diretamente a } \\
\text { respeito da resiliência na } \\
\text { cadeia de suprimentos ou } \\
\text { constar facilitadores para a } \\
\text { criação de resiliência na } \\
\text { cadeia de suprimentos. }\end{array}$ & $\begin{array}{l}\text { Não se referir diretamente à } \\
\text { resiliência na cadeia de } \\
\text { suprimentos, não constar } \\
\text { facilitadores para a criação de } \\
\text { resiliência na cadeia de } \\
\text { suprimentos. }\end{array}$ & \\
\hline \multirow[t]{5}{*}{2} & Acesso & $\begin{array}{l}\text { Possuir acesso ao } \\
\text { trabalho, estar redigido em } \\
\text { inglês ou português. }\end{array}$ & $\begin{array}{l}\text { Não possuir acesso ao } \\
\text { trabalho, não estar redigido em } \\
\text { inglês ou português. }\end{array}$ & \multirow{5}{*}{$\begin{array}{l}\text { Leitura da } \\
\text { Introdução } \\
\text { e } \\
\text { conclusão. } \\
\text { Analisar } \\
\text { acesso e } \\
\text { qualidade } \\
\text { do } \\
\text { periódico. }\end{array}$} \\
\hline & Qualidade & $\begin{array}{l}\text { Periódico cientifico com } \\
\text { revisão de pares }\end{array}$ & $\begin{array}{l}\text { Jornais de negócios, revistas } \\
\text { correntes, conferencias, livros e } \\
\text { sites. Periódico cientifico sem } \\
\text { revisão de pares }\end{array}$ & \\
\hline & Marco teórico & $\begin{array}{l}\text { Conceitos de resiliência na } \\
\text { cadeia de suprimentos, em } \\
\text { um contexto de gestão de } \\
\text { operações e/ou gestão de } \\
\text { cadeia de suprimentos } \\
\text { como foco do trabalho. }\end{array}$ & $\begin{array}{l}\text { Conceitos referentes à ciência } \\
\text { dos materiais ou do meio } \\
\text { ambiente, fisiologia, saúde, } \\
\text { estudos urbanísticos ou utiliza a } \\
\text { resiliência como fator periférico. }\end{array}$ & \\
\hline & $\begin{array}{l}\text { Unidade de } \\
\text { análise }\end{array}$ & $\begin{array}{l}\text { Tratar de resiliência em } \\
\text { organizações e o } \\
\text { relacionamento de } \\
\text { indivíduos internamente e } \\
\text { externamente a essas. }\end{array}$ & $\begin{array}{l}\text { Tratar de resiliência em } \\
\text { comunidades, materiais, } \\
\text { ambiente, ou indivíduos não } \\
\text { relacionados a organizações. }\end{array}$ & \\
\hline & $\begin{array}{l}\text { Definir os } \\
\text { facilitadores } \\
\text { a resiliência } \\
\text { descritos }\end{array}$ & $\begin{array}{l}\text { Definir claramente os } \\
\text { facilitadores descritos. }\end{array}$ & $\begin{array}{l}\text { Não permitir identificar } \\
\text { claramente os facilitadores a } \\
\text { resiliência, ou não os definir ou } \\
\text { explicar. }\end{array}$ & \\
\hline
\end{tabular}

Fonte: Autores

\subsection{Análise de conteúdo}

As análises do presente estudo foram feitas com auxílio do método de análise de conteúdo de acordo com o que propõem Bauer e Gaskell (2003), Bardin (2008), Bringer (2006), Hutchison, Johnston e Breckon (2010), Johnston (2006) e Krippendorff (2013). Os artigos foram inicialmente lidos e, após essas leituras, os artigos foram inseridos no software QDA Miner para a realização das análises.

Com auxílio do software, após a leitura detalhada e crítica dos artigos resultantes da revisão sistemática, foram separados frases e partes dos textos de cada artigo que caracterizavam os facilitadores, surgindo assim uma lista de códigos. Dessa forma, a criação das codificações e suas ramificações permitiram posteriores comparações. As categorizações e as codificações são tentativas de se agrupar passagens que se refiram a um mesmo tema. Dessa forma, relações são 
mais facilmente encontradas e demonstradas, podendo-se assim estabelecer relações entre diversos autores que se refiram a um mesmo tema (GIBBS, 2009). Para Bringer (2006), a construção das codificações pode se iniciar com a separação do texto em partes discretas e, a partir de então, os termos são agrupados nas respectivas codificações, ou como no caso que geralmente é utilizado nos softwares, no qual as codificações podem ser alteradas a qualquer momento da análise. Cabe destacar que essas codificações foram atualizadas a medida que surgiam novas informações na leitura dos artigos (HUTCHISON; JOHNSTON; BRECKON, 2010).

No que diz respeito às ferramentas utilizadas para a análise de conteúdo a partir do software, optou-se pelo relatório de frequência de codificação que permitiu a visualização dos códigos utilizados, bem como uma série de informações numéricas a respeito desses, como a frequência de codificação e o número de palavras dos segmentos. Já a codificação por variável (também utilizada), relacionou as codificações existentes em relação às variáveis, sendo útil para a identificação de semelhanças em potencial ou ainda para avaliar a relação entre esses códigos e outras variáveis (QDA MINER, 2015).

As ferramentas acima apresentadas foram utilizadas como prévia para a análise de co-ocorrência. A co-ocorrência possibilita a localização de relações entre os códigos ou entre os casos (QDA MINER, 2015). Para Manly (2008), a análise de agrupamento busca agrupar os objetos em classes de forma que objetos semelhantes estejam na mesma classe; ou seja, considerando as proximidades entre essas codificações. Para a análise de conteúdo desta pesquisa, foi utilizada a análise de agrupamentos (ou cluster), considerando para a construção das análises o índice de similaridade entre as codificações, e, para a definição do número de grupos a ser considerado, foi utilizado o metódo hierárquico. Para Robredo e Cunha (1998), o índice de similaridade mantém um domínio fechado de [0;1] e esse índice representa co-ocorrência entre dois termos. De acordo com o sugerido por Meyer et al. (2004), foi utilizado o cálculo de Sorensen, devido ao domínio apresentado do índice. O cálculo de Sorensen detecta melhor a presença da co-ocorrência, ao valorizá-la mais que a ocorrência das codificações.

\section{ANÁLISE E DISCUSSÃO DOS RESULTADOS}

\subsection{Facilitadores à resiliência na cadeia de suprimentos}

Os facilitadores encontrados sobre a geração de resiliência na cadeia de suprimentos foram diversos. Alguns autores (PETTIT; FIKSEL; CROXTON, 2010; SCHOLTEN; SCOTT; FYNES, 2014; JOHNSON; ELLIOTT; DRAKE, 2013; SHEFFI; RICE, 2005) consideram pontos distintos para cada facilitador e esta riqueza de detalhamento será evidenciada na discussão apresentada nesta seção. O Quadro 4 apresenta os facilitadores, bem como uma breve definição de cada um deles e as principais referências utilizadas para a construção da definição. 


\section{Agilidade de reação a rupturas}

A agilidade na reação às rupturas está relacionada à rápida recuperação da cadeia de suprimentos após uma ruptura, sendo esta fundamental para se responder a rupturas inesperadas (BLACKHURST et al., 2005; PETTIT; FIKSEL; CROXTON, 2010). De forma complementar, Pettit, Fiksel e Croxton (2010) afirmam que a agilidade é fundamental para se responder a rupturas inesperadas. Desta forma, a agilidade é um facilitador relevante na criação da resiliência nas cadeias de suprimentos. Para Christopher e Peck (2004) e Jüttner e Maklan (2011), o facilitador visibilidade pode ser considerado antecedente para a agilidade.

\section{Comunicação}

$\mathrm{Na}$ busca por agilidade de reação, a comunicação é outro facilitador a ser destacado. Uma empresa que possui protocolos de comunicação definidos e que mantém rotinas de comunicação frequentes pode identificar e reagir mais rapidamente a uma ruptura, uma vez que a informação flui, chegando nos pontos adequados para reação (BLACKHURST; DUNN; CRAIGHEAD, 2011; WIELAND; WALLENBURG, 2013).

\section{Colaboração}

A comunicação está relacionada à colaboração, que, por sua vez, é outro facilitador a ser considerado. Johnson, Elliott e Drake (2013) afirmam que a colaboração pode aumentar a confiança mútua entre os elos da cadeia. Este facilitador possui intensa participação na construção da resiliência, considerando que uma maior proximidade advinda da colaboração entre as empresas pode aumentar a capacidade de visibilidade de eventos que tendem a ameaçar o desempenho organizacional e da cadeia como um todo.

\section{Visibilidade}

A visibilidade está relacionada à identificação dos recursos, dos riscos e de como as rupturas se propagam. Entender tais questões auxilia as empresas na prevenção e na recuperação eficiente das rupturas, pois, a partir do conhecimento da estrutura da cadeia, da forma como essa reage às influências externas e de onde estão os recursos, as empresas podem se preparar e responder mais eficientemente às rupturas (BLACKHURST et al., 2005; BLACKHURST; DUNN; CRAIGHEAD, 2011). Com uma maior visibilidade de eventos que tendem a ameaçar o desempenho empresarial, torna-se mais fácil a prevenção e mitigação de riscos. A título de exemplo, quando uma empresa possui visibilidade das rotas possíveis para seus fornecedores, bem como da situação em que essas se encontram em momentos de ruptura, essas empresas podem alterar as rotas, mitigando os impactos.

\section{Grupos interfuncionais}

A presença de grupos interfuncionais pode se mostrar útil para o aumento da 
visibilidade na cadeia de suprimentos, evitando a visão de silos funcionais (BLACKHURST; DUNN; CRAIGHEAD, 2011). Dentro dos grupos interfuncionais encontram-se pessoas com formação, visão e conhecimentos diferentes acerca de como resolver diferentes problemas; assim a tendência a construir soluções mais rápidas e de melhor qualidade é mais significativa (BLACKHURST; DUNN; CRAIGHEAD, 2011; WIELAND; WALLENBURG, 2013). 
Quadro 4 - Facilitadores à geração da resiliência

Facilitadores

Agilidade de reação

\section{às rupturas}

Colaboração

Comunicação

Estrutura da cadeia de

suprimentos

Flexibilidade

Considera as adaptações e o tempo que ações necessárias à recuperação sejam tomadas.

Definição

Autores

Habilidade de trabalhar efetivamente com outra entidade para o benefício mútuo.

A troca de informações de forma a reduzir a assimetria entre o fabricante e seus fornecedores.

Formato que a cadeia de suprimentos possui, inclui fatores como distância dos fornecedores, localização da empresa, infraestrutura de transporte.

Capacidade de alterar um processo, produto/fornecedor ou cliente/rede Logística de forma a recuperar de uma ruptura. Denota capacidade de se reestruturar, habilidade de mudar as entradas ou saídas após uma ruptura.

Gestão de riscos O gerenciamento de riscos é constituído pelas formas de monitoramento, conhecimento e prevenção de riscos. O gerenciamento de riscos provê formas de se preparar para os ricos que puderem ser previstos com antecedência.

\section{Gestão do} conhecimento Conhecimento acumulado em eventos parecidos auxilia a tomar ações e estabilizar as cadeias de
suprimento mais rapidamente.

Grupos
interfuncionais

Times compostos por pessoas de funções diferentes; estes são capazes de visualizar toda a cadeia e facilitam o retorno mais rápido e eficientemente de uma ruptura, a partir da influência sobre os clientes e os fornecedores.

Redundância A redundância é sobreposição de operações, processos, produtos, fornecedores ou sistemas, a partir de uma capacidade extra pré-existente, que é acionada a partir de uma ruptura. Compreende estoque de segurança.

Saúde financeira Capacidade de absorver possíveis flutuações no fluxo de caixa da empresa, empresa com mais saúde financeira pode fornecer incentivos econômicos, cultivando fornecedores adicionais.

Tecnologia Mecanismos de tecnológicos como localização de posição global (GPS), tecnologia de identificação automática, câmeras, segurança digital e da informação.

Visibilidade Permite que as empresas localizem as possíveis rupturas. É o entendimento que a empresa possui sobre a cadeia, sua capacidade de identificar riscos e recursos e de conhecer como as rupturas se propagam.
Jüttner e Maklan (2011)

Pettit, Fiksel e Croxton (2010); Johnson, Elliott e Drake (2013)

Wieland e Wallenburg (2013)

Blackhurst et al. (2005); Craighead et al. (2007); Thun e Hoenig (2011); Gong et al. (2014)

Rice e Caniato (2003); Pettit, Fiksel e Croxton (2010)

Blackhurst et al. (2005); BuenoSolano e Cedillo-Campos (2014); Ambulkar, Blackhurst e Grawe (2015)

Blackhurst, Dunn e Craighead (2011); Scholten, Scott e Fynes (2014)

Demmer, Vickery e Calantone

(2011); Blackhurst, Dunn e

Craighead (2011); Khan,

Christopher e Creazza (2012)

Rice e Caniato (2003); Johnson,

Elliott e Drake (2013); Scholten, Scott e Fynes (2014)

Pettit, Fiksel e Croxton (2010); Zhang, Dadkhah e Ekwall (2011) Zhang, Dadkhah e Ekwall (2011)

Blackhurst et al. (2005); Pettit, Fiksel e Croxton (2010);

Blackhurst, Dunn e Craighead (2011); Johnson, Elliott e Drake (2013)

Fonte: Elaborado pelos autores 


\section{Flexibilidade}

A flexibilidade está relacionada à capacidade de reestruturação da empresa, podendo auxiliar na alteração de fornecedores, nas rotas de distribuição, nos produtos ou nas redes logísticas, gerando a recuperação de uma ruptura (RICE; CANIATO, 2003; PETTIT; FIKSEL; CROXTON, 2010). A importância do facilitador flexibilidade é ainda reafirmada pelo trabalho de Jüttner e Maklan (2011). De acordo com estes autores, dados empíricos demonstram que tal facilitador auxiliou duas das empresas estudadas a responderem mudanças imprevisíveis, satisfazendo a demanda crescente a um baixo custo e, assim, tornando-as mais resilientes. Nota-se que a flexibilidade não está ligada somente às relações com fornecedores, mas também no lado da demanda do cliente, nas rotas de distribuição, no gerenciamento de inventários, entre outros.

Assume-se como diferenciação entre agilidade de reação às rupturas e à flexibilidade o fato de a segunda consistir na facilidade para a realização de alterações, o que não necessariamente implica em agilidade de resposta a partir de um plano pré-estabelecido (de contingência, por exemplo) (RICE; CANIATO, 2003; JÜTTNER; MAKLAN, 2011). Tais pontos demonstram a relevância da flexibilidade para a resiliência na cadeia de suprimentos.

\section{Estrutura da cadeia de suprimentos}

Questões como o número de nós presentes na cadeia de suprimentos, a localização dos mesmos, a infraestrutura viária, a presença ou a ausência de fornecedores em pontos estratégicos afetam não somente as questões referentes à resiliência, mas também a cadeia de suprimentos de forma geral. Tal estrutura pode promover a resiliência por meio da existência de rotas curtas entre empresas e fornecedores, o que reduz os riscos de problemas de transporte, ou por meio da localização de fornecedores em locais seguros e pouco suscetíveis às rupturas. Cabe destacar que, embora os autores possuam foco nas relações de estrutura referentes aos fornecedores (visão de suprimentos), há referências à localização dos clientes (CRAIGHEAD et al., 2007; SCHOLTEN; SCOTT; FYNES, 2014; GONG et al., 2014).

\section{Gestão de riscos}

A gestão dos riscos está relacionado à visibilidade, visto que, baseado na visibilidade que a empresa possui da cadeia de suprimentos e em suas análises preditivas, as empresas buscam com o gerenciamento preparar-se contra alguns riscos (BLACKHURST et al., 2005; BLACKHURST; DUNN; CRAIGHEAD, 2011). Para Zsidisin et al. (2004), a implantação da gestão dos riscos possibilita a geração de informações a respeito de potenciais rupturas. Essas informações podem ser utilizadas, por exemplo, para criar estratégias que reduzam as chances de que essas rupturas ocorram ou reduzam o impacto dessas, demonstrando a significância desse facilitador para a geração de resiliência. 
Integrado a gestão de riscos, o plano de contingência apresenta significativa contribuição para a resiliência na cadeia de suprimentos. De acordo com Blackhurst, Dunn e Craighead (2011), cinco de sete empresas entrevistadas discutiram a positiva contribuição da existência e da execução destes durante uma ruptura. Para Craighead et al. (2007) e Blackhurst, Dunn e Craighead (2011), o plano de contingência é um plano previamente definido para ter início imediato após a ruptura. Em um cenário ideal, o plano de contingência deve ser proativo por natureza e essa proatividade é gerada com ações que são disparadas de acordo com interrupções específicas; ou seja, o plano de contingência deve possuir execução automática após as rupturas para ser efetivo. Nota-se que esse facilitador auxilia efetivamente à recuperação de rupturas na cadeia de suprimentos, desde que bem elaborado.

\section{Redundância}

No que se refere à redundância, este trabalho seguirá a linha dos autores Rice e Caniato (2003), Johnson, Elliott e Drake (2013) e Scholten et al (2014). Esses autores afirmam que a redundância é sobreposição de operações, fornecedores ou sistemas, pressupondo a existência de uma capacidade extra pré-existente. A redundância inclui a subutilização de recursos, a existência de funcionários em excesso, a jurisdições sobrepostas e canais de distribuição e a comunicação em paralelos. O facilitador redundância, por vezes, é denominado como estoque de segurança. Sheffi e Rice (2005) consideram estoques de segurança uma forma de redundância. Nesse sentido, para Schmitt e Singh (2012), os estoques de segurança representam o acúmulo de matérias-primas ou produtos acabados como forma de assegurar o abastecimento em casos de rupturas. Portanto, o estoque de segurança pode ser considerado como pertencente à redundância, visto que representa uma capacidade pré-existente.

No que se refere às políticas de redundância e estoque, Schmitt e Singh (2012) destacam a necessidade de se tomar alguma precaução com tal técnica. Isso deve ser feito, pois em um ambiente com grande variedade de produtos e matériasprimas, a política de redundância pode elevar demasiadamente os estoques, observando que os níveis de inventário devem sempre levar em conta os custos e os riscos de ruptura. A redundância contribui com a resposta à ruptura, podendo então ser considerada um facilitador à geração de resiliência na cadeia de suprimentos (RICE; CANIATO, 2003; SCHMITT; SINGH, 2012; JOHNSON; ELLIOTT; DRAKE, 2013; SCHOLTEN; SCOTT; FYNES, 2014).

\section{Saúde financeira}

A saúde financeira refere-se à capacidade de suportar flutuações no fluxo de caixa, como em casos nos quais durante a ruptura a empresa pode necessitar de capital para diversificar o portfólio, alterar as suas margens, incentivar financeiramente as empresas com problemas ou, ainda, para cultivar novos fornecedores (PETTIT; FIKSEL; CROXTON, 2010; ZHANG; DADKHAH; EKWALL, 
2011). Como a saúde financeira oferece auxílio nos momentos de rupturas, este pode ser considerado como um facilitador à geração de resiliência na cadeia de suprimentos.

\section{Tecnologia}

A tecnologia pode ser definida como o desenvolvimento de mecanismos que protejam a empresa de perdas financeiras ou de informações. Considerando a influência desse facilitador à resiliência na cadeia de suprimentos, Pettit, Fiksel e Croxton (2010) e Zhang, Dadkhah e Ekwall (2011) definem a tecnologia como a criação de mecanismos de defesa ante a ruptura. A tecnologia, quando focada em segurança, busca identificar rapidamente a ruptura e, desta forma, preparar as empresas para evitar problemas tais quais ataques a websites. Um exemplo desse tipo de ataque é o caso da empresa Target que, em 2013 após um ataque cibernético, teve os dados de alguns de seus clientes expostos. Essa empresa, além de passar por uma crise posterior ao fato, teve seus resultados financeiros afetados, necessitando cortar o número de funcionários e desembolsando cerca de 10 milhões de dólares como forma de acordo judicial (MELO, 2015).

A tecnologia pode referir-se também a questões como busca de mecanismos que preparem a cadeia para sabotagens ou assaltos. Esse facilitador pode gerar mais visibilidade da cadeia e facilitar a comunicação, como por meio da utilização de rastreamento via GPS (PETTIT; FIKSEL; CROXTON, 2010; HEARNSHAW; WILSON, 2013). Ainda no que se refere à tecnologia, Khan e Estay (2015) realizaram uma revisão sistemática a respeito de resiliência digital e destacaram que a temática está em seus estágios iniciais. Apesar da importância do tema, a literatura a respeito é restrita e não foram localizados frameworks específicos para a resiliência digital. Este trabalho considerará pontos referentes à resiliência digital como pertencentes ao facilitador Tecnologia, visto que, como se pode notar, tais ataques são intencionais e muitas vezes podem ser mitigadas com tecnologias ligadas à segurança digital.

\section{Gestão do conhecimento}

Um dos facilitadores também levantado é a Gestão do conhecimento. Scholten, Scott e Fynes (2014) encontraram, em boa parte dos casos estudados, que a experiência, o aprendizado com casos anteriores e os treinamentos auxiliam a recuperação das rupturas. Essa gestão normalmente se dá com treinamentos exclusivos para reações a rupturas ou em experiências em rupturas anteriores. Esse facilitador contribui para que os gestores tomem decisões mais exatas, evitando que a ruptura se agrave e impossibilite o retorno à situação desejada. Pode-se claramente destacar este último como um facilitador à geração de resiliência na cadeia de suprimentos. 


\subsection{Relação entre facilitadores e agrupamentos}

Há diversas nomenclaturas e agrupamentos de facilitadores na literatura. O artigo de Pettit, Fiksel e Croxton (2010) é um exemplo, pois as classificações atribuídas aos facilitadores por esses autores se diferenciam das que foram anteriormente apresentadas. Isto pode ser visto principalmente pela existência de tipos distintos de flexibilidade, além de considerar o facilitador adaptabilidade (considerado aqui como integrante de flexibilidade e como parte do treinamento). A Figura 3 apresenta uma comparação entre o trabalho de Pettit, Fiksel e Croxton (2010) e alguns facilitadores identificados neste estudo, destacando os principais autores utilizados para a identificação. Cabe destacar que nem todos os facilitadores mapeados neste estudo tiveram equivalência encontrada ao trabalho de Pettit, Fiksel e Croxton (2010).

Figura 3 - Equivalência dos facilitadores de Pettit, Fiksel e Croxton (2010)

\begin{tabular}{|c|c|c|}
\hline $\begin{array}{l}\text { Pettit, Fiksel e Croxton } \\
\text { (2010) }\end{array}$ & Equivalente & Principais autores \\
\hline Capacidade & Redundância & $\begin{array}{l}\text { Rice e Caniato (2003); Johnson, Elliott e Drake } \\
\text { (2013); Scholten, Scott e Fynes (2014) }\end{array}$ \\
\hline Antecipação & Gestão dos riscos & $\begin{array}{l}\text { Blackhurst et al. (2005); Bueno-Solano e Cedillo- } \\
\text { Campos (2014); Ambulkar, Blackhurst e Grawe } \\
\text { (2015) } \\
\text { Blackhurst et al. (2005); Blackhurst, Dunn e } \\
\text { Craighead (2011); Pettit, Fiksel e Croxton (2010); } \\
\text { Johnson, Elliott e Drake (2013) }\end{array}$ \\
\hline Recuperação & $\begin{array}{l}\text { Comunicação } \\
\text { Agilidade de reação a rupturas }\end{array}$ & $\begin{array}{l}\text { Wieland e Wallenburg (2013) } \\
\text { Jüttner e Maklan (2011) }\end{array}$ \\
\hline Dispersão & $\begin{array}{l}\text { Grupos Interfuncionais } \\
\text { Visibilidade }\end{array}$ & $\begin{array}{l}\text { Blackhurst, Dunn e Craighead (2011) } \\
\text { Blackhurst et al. (2005); Blackhurst, Dunn e } \\
\text { Craighead (2011); Pettit, Fiksel e Croxton (2010); } \\
\text { Johnson, Elliott e Drake (2013) }\end{array}$ \\
\hline Organização & $\begin{array}{l}\text { Gestão do conhecimento } \\
\text { Grupos Interfuncionais }\end{array}$ & $\begin{array}{l}\text { Blackhurst, Dunn e Craighead (2011); Scholten, } \\
\text { Scott e Fynes (2014) } \\
\text { Blackhurst, Dunn e Craighead (2011) }\end{array}$ \\
\hline Posição de Mercado & $\begin{array}{l}\text { Flexibilidade } \\
\text { Comunicação }\end{array}$ & $\begin{array}{l}\text { Rice e Caniato (2003); Pettit, Fiksel e Croxton } \\
\text { (2010) } \\
\text { Wieland e Wallenburg (2013) }\end{array}$ \\
\hline
\end{tabular}

Fonte: Elaborado pelos autores

Reafirmando a existência de diferentes agrupamentos e nomenclaturas, a Figura 4 apresenta uma comparação entre o trabalho de Scholten, Scott e Fynes (2014) e facilitadores deste estudo. 
Figura 4 - Equivalência dos facilitadores de Scholten, Scott e Fynes (2014)

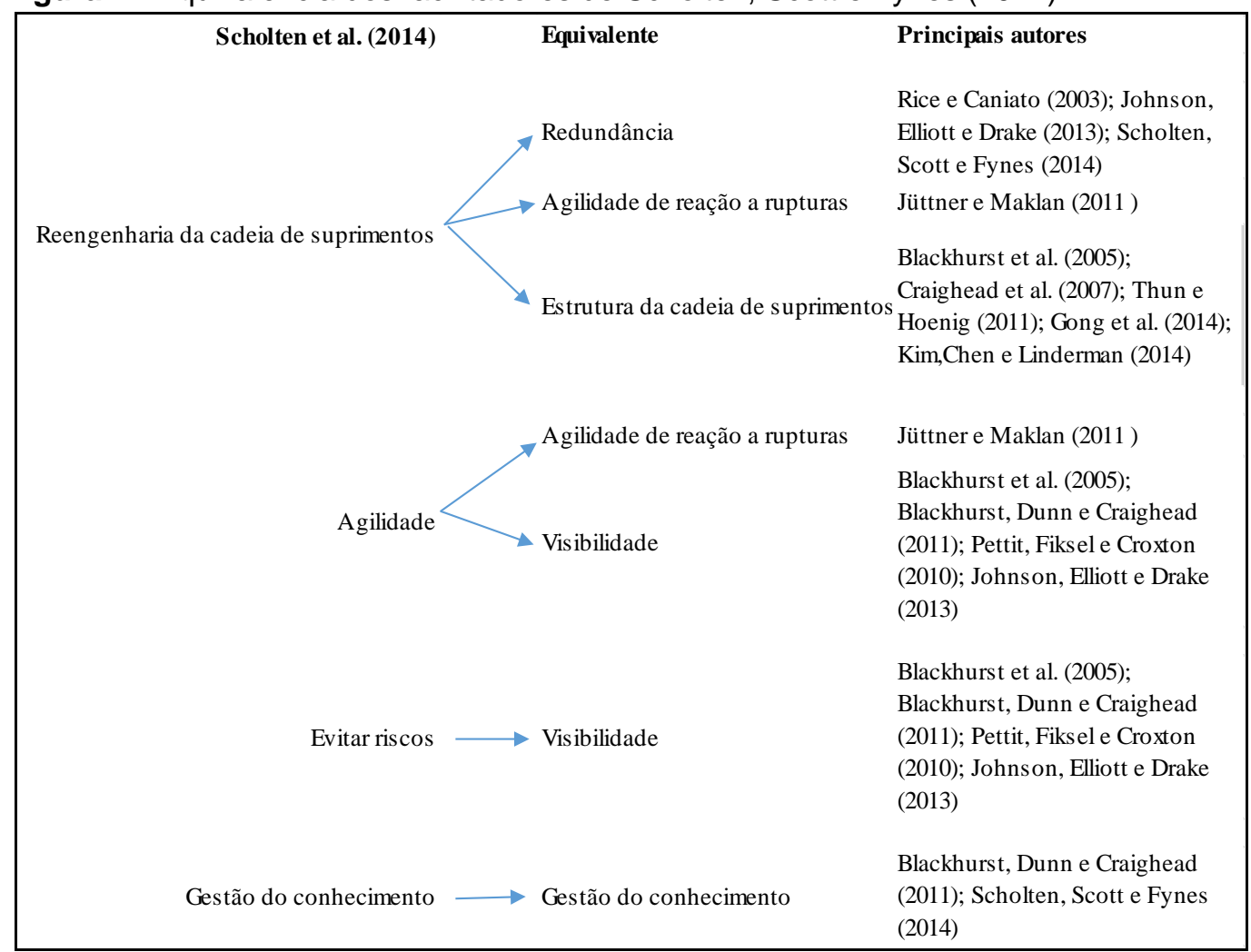

Fonte: Elaborado pelos autores

Posteriormente, analisou-se o número de trabalhos nos quais se observou cada um dos facilitadores selecionados, destacando os facilitadores que possuíam maior relevância na literatura revisada. A Figura 5 demonstra o resultado dessa análise, e para a construção dessa figura considerou-se o número de artigos que citavam cada facilitador, desconsiderando o número de vezes que esse facilitador se repetia no interior do artigo. Com isso, pretende-se evitar vieses gerados por artigos especializados em um único facilitador, o que elevaria os índices deste. 
Figura 5 - Porcentagem de casos por facilitador

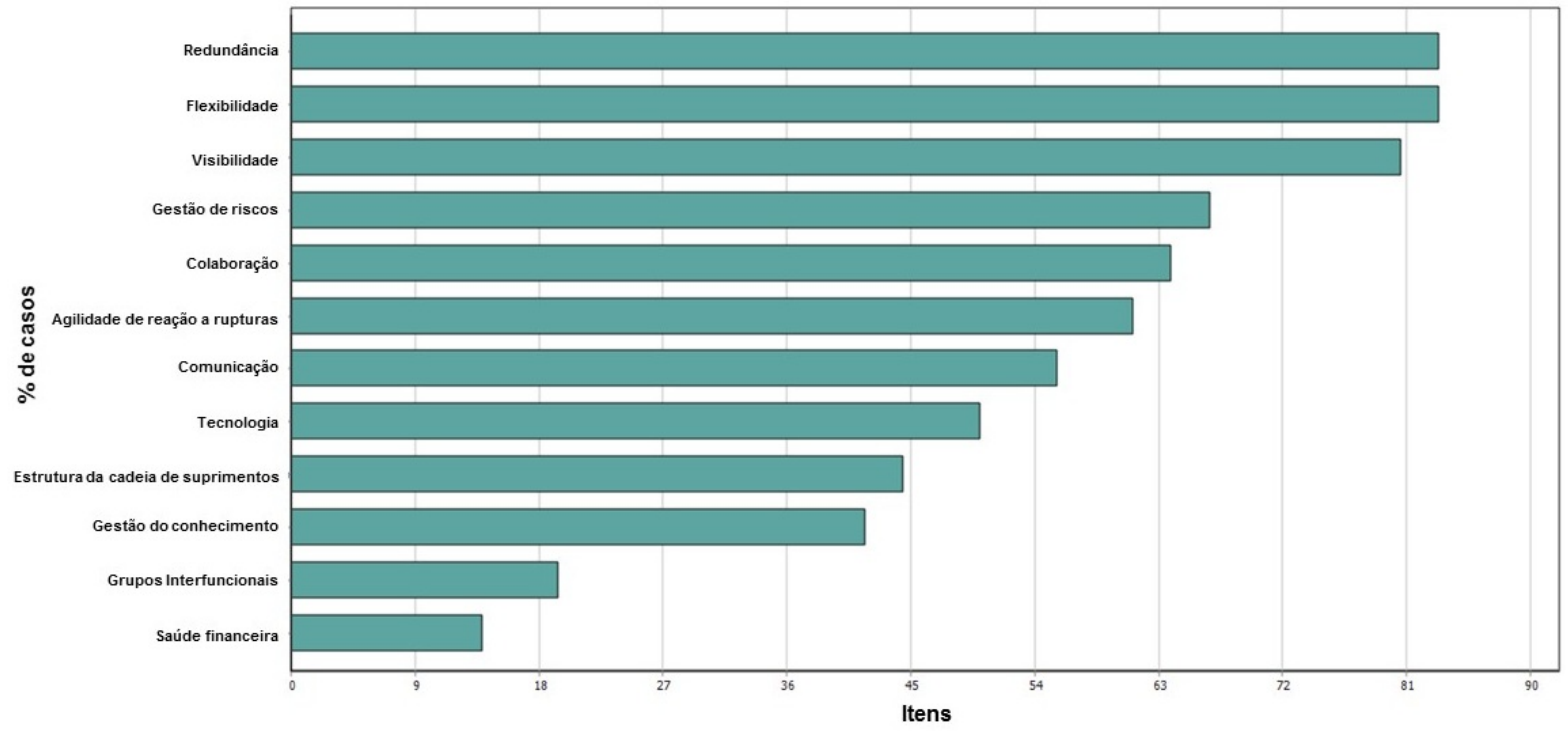

Fonte: Dados da pesquisa

Para que se possa observar quais facilitadores foram citados por cada autor, um relatório de codificação por variável foi construído. A partir dessa análise, o Quadro 5 expõe os facilitadores ligados aos autores que os comentaram em seus textos. 
Agilidade de reação

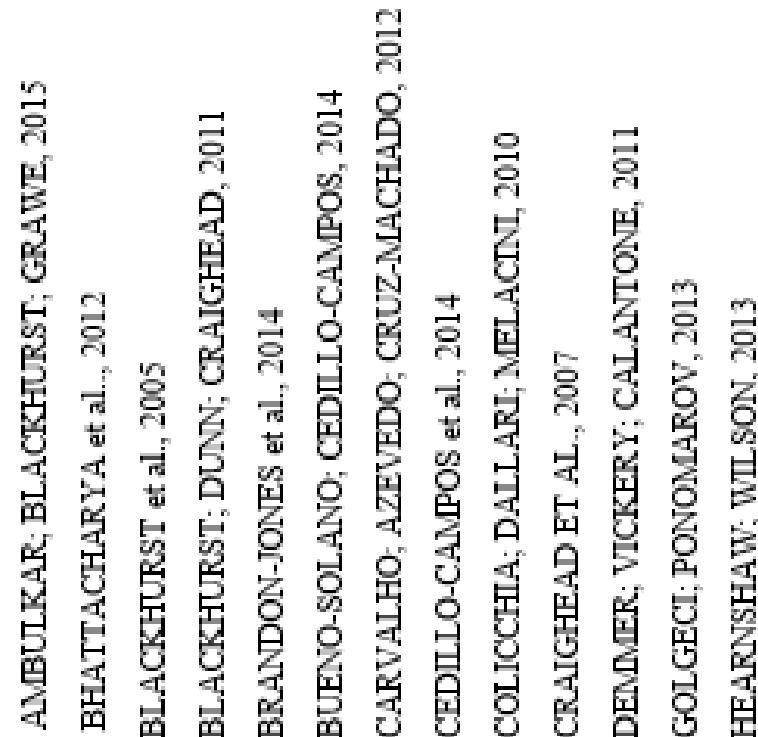

a rupturas

Colaboração

\section{Comunicação}

Estrutura da cadeia

de suprimentos

Flexibilidade

Gestão de riscos

Gestão do

conhecimento

Grupos

Interfuncionais

Redundância

Saúde financeira

Tecnologia

Visibilidade

Fonte: Elaborado com base em diversos autores 
Outra análise possível é a de agrupamento dos facilitadores. Com o auxílio do software QDA Miner, uma análise de co-ocorrência foi feita de acordo com o definido na seção 3.2. Considerando os facilitadores à geração de resiliência na cadeia de suprimentos pré-definidos no Quadro 4, foi analisado inicialmente 0 dendrograma. A partir da análise dos resultados do dendrograma, optou-se pela utilização de seis grupos, utilizando o método de K-means. Dessa forma, a Figura 6 demonstra os resultados da análise de co-ocorrência. Cabe destacar que o tamanho dos círculos representa o número de citações do facilitador.

Figura 6 - Relações entre os facilitadores

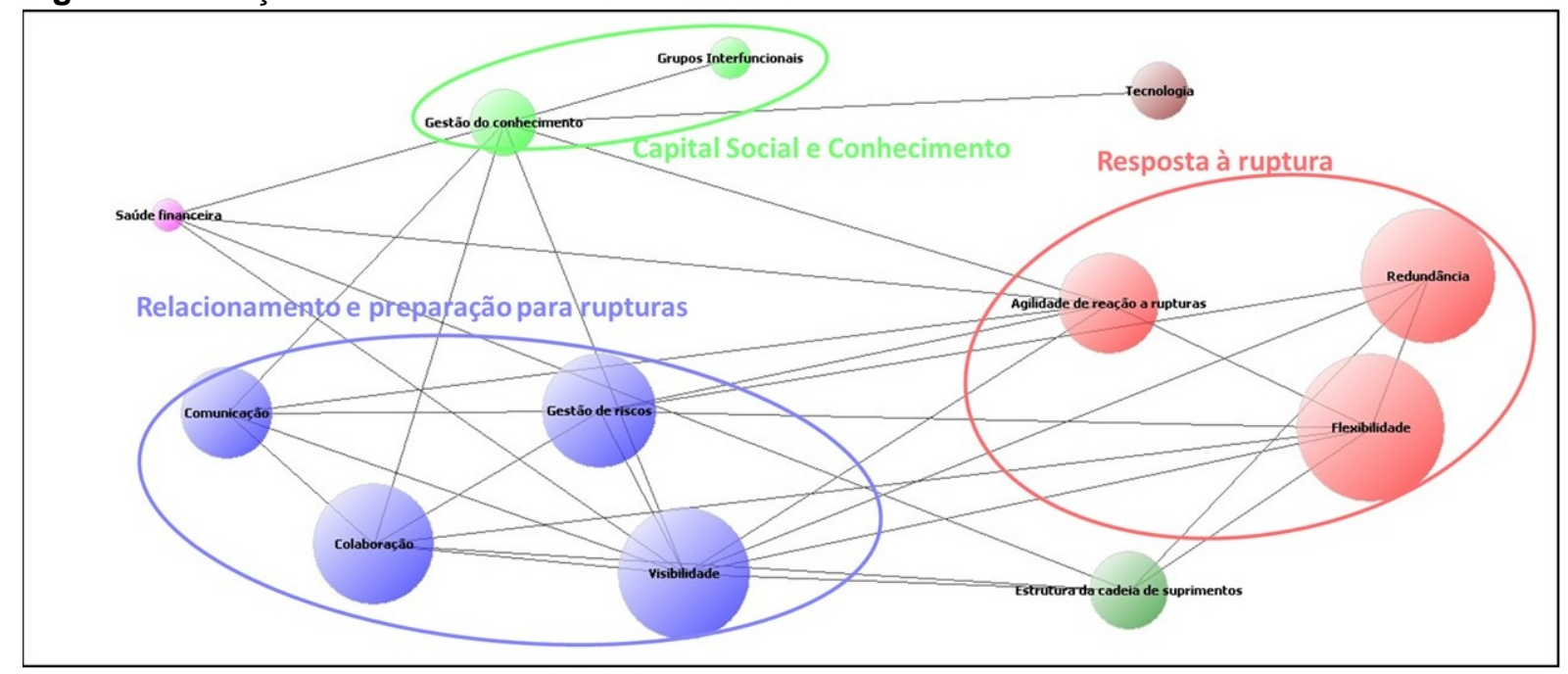

Fonte: Elaborado pelos autores

Nota-se que alguns facilitadores, como é o caso da tecnologia, estrutura da cadeia de suprimentos e saúde financeira encontram-se em grupos de facilitadores isolados, no nível de agrupamento selecionado. Este trabalho optou por manter tais facilitadores, pois embora eles encontrem-se isolados, pesquisas empíricas futuras podem localizar novas inter-relações. Observando-se também o grupo em vermelho, que é formado por facilitadores relacionados à resposta às rupturas, percebe-se a presença dos facilitadores flexibilidade e agilidade de reação às rupturas, e acreditase que a proximidade desses facilitadores se dê devido ao fato de a flexibilidade possuir um relacionamento próximo à agilidade de reação às rupturas. Para alguns autores, o fato de a empresa ser flexível pode influenciar a sua agilidade para reagir a uma ruptura (TANG, 2007; PETTIT; FIKSEL; CROXTON, 2010; GONG et al., 2014; URCIUOLI et al., 2014).

Outro facilitador presente nesse grupo é a redundância. Segundo Jüttner e Maklan (2011), a existência de redundância possibilitou que duas das empresas por eles estudadas, conseguissem atingir capacidades de produção regionais, e assim conseguir rapidamente suprir demandas regionais inesperadas. Tal constatação demonstra como a redundância pode influenciar na agilidade de reação às rupturas, visto que possibilitou uma rápida resposta à necessidade. Isso reforça o 
relacionamento encontrado entre esses facilitadores na análise de conteúdo realizada.

O maior agrupamento (em azul) é formado por facilitadores que envolvem o relacionamento e a preparação para as rupturas. Pode-se observar que mesmo dentro desse último agrupamento, existem facilitadores mais intimamente ligados. Um exemplo é a colaboração e a visibilidade. A colaboração encontra-se fortemente relacionada à visibilidade, pois, de acordo com Brandon-Jones et al. (2014), empresas que possuem uma maior colaboração podem possuir uma maior visibilidade da cadeia de suprimentos em razão do aumento da confiança mútua. Assim, acredita-se que, devido a essa relação, os autores tendam a primeiro citar o facilitador colaboração e posteriormente mencionar a visibilidade. Outro ponto de destaque é que essa relação entre visibilidade de colaboração facilita também a gestão dos riscos, visto que com uma maior visibilidade da cadeia torna-se mais fácil conhecer os riscos presentes nessa. Portanto, a colaboração torna-se uma atividade imprescindível nas empresas que pretendam construir práticas que gerem resiliência na cadeia de suprimentos.

Observa-se na Figura 6 que o facilitador colaboração possui também uma forte relação com a comunicação, como já comentado por Blackhurst, Dunn e Craighead (2011). Esses facilitadores estão inter-relacionados por serem facilitadores iniciais a resiliência na cadeia de suprimentos. Assim, acredita-se que há uma tendência que ao citar a comunicação, os autores à relacionem com a colaboração e vice e versa, o que gera essa ligação próxima. Destaca-se ainda que a colaboração, a comunicação e a visibilidade, além de encontrarem-se relacionadas, contribuem efetivamente para a prevenção e a mitigação das rupturas (PONOMAROV; HOLCOMB, 2009; PETTIT; FIKSEL; CROXTON, 2010; JÜTTNER; MAKLAN, 2011; JOHNSON; ELLIOTT; DRAKE, 2013; SCHOLTEN; SCOTT; FYNES, 2014).

Finalmente, nota-se a formação de um agrupamento que contém os facilitadores: grupos interfuncionais e gestão do conhecimento. Esses facilitadores estão ligados ao investimento em capital social e conhecimento e, portanto, a formação desse agrupamento indica os autores que tendem a comentar conjuntamente e provavelmente relacionando esses dois facilitadores. Observa-se que ambos os facilitadores estão ligados ao conhecimento de uma ou várias pessoas e às formas de alinhar esse conhecimento de modo a gerar resiliência.

\section{CONCLUSÕES}

No atual cenário mundial de instabilidades econômicas, crises políticas e mudanças climáticas, as rupturas são eventos inerentes a qualquer cadeia de suprimentos, as quais não podem ser ignoradas, caso a empresa aspire por continuidade de seus negócios. Percebe-se que a identificação e a aplicação de facilitadores nas atividades estratégicas podem auxiliar empresas e suas cadeias de suprimentos na reação contra rupturas (incitadas por uma fonte interna ou externa). 
O desenvolvimento de facilitadores nas atividades empresariais possibilita, portanto, o preparo das empresas para lidarem com situações inusitadas, sendo estas capazes de se tornarem mais resilientes em um cenário de ruptura e manterem suas operações funcionando, mesmo com índices de desempenho inferiores.

O presente estudo responde as duas questões de revisão identificadas anteriormente. Foram caracterizados doze facilitadores para o desenvolvimento de uma cadeia de suprimentos resiliente por meio de uma revisão sistemática da literatura. São eles: agilidade de reação a rupturas, colaboração, comunicação, estrutura da cadeia de suprimentos, flexibilidade, gestão de riscos, gestão do conhecimento, grupos interfuncionais, redundância, saúde financeira, tecnologia e visibilidade. A partir desse mapeamento, foram analisadas diferentes nomenclaturas existentes aos facilitadores na literatura, seguida de análises da distribuição e do agrupamento desses facilitadores. Foi observado durante a revisão que grande parte dos facilitadores se encontra relacionado. Isso dificulta a definição de limites claros entre os mesmos, possibilitando discussões a partir da observância de tais pontos. O presente trabalho contribui, portanto, com a definição de tais limites, possibilitando que estudos futuros tomem-no por referência, provendo a identificação, a definição e a análise dos facilitadores aqui mapeados em setores distintos - seja manufatura ou serviços.

Como contribuição à literatura, este estudo adiciona a temática de gestão de cadeia de suprimentos resiliente ao identificar facilitadores à criação da resiliência na cadeia e agrupá-los de acordo com suas características (como discutido previamente) de modo a visualizar facilitadores de maior predominância a criação de ações resilientes em cadeias de suprimentos. No que se refere às implicações gerenciais, este artigo oferece uma visão geral a respeito de fatores críticos em relação à criação de resiliência na cadeia de suprimentos, possibilitando o entendimento da temática por empresas que pretendam desenvolver tal habilidade em seus negócios.

Como todo estudo, este apresenta algumas limitações. A primeira delas refere-se à ausência de dados empíricos. O propósito aqui era realizar um levantamento bibliográfico, a partir de um método robusto de revisão (revisão sistemática de literatura). Outra limitação seria a opção por focar nos facilitadores e suas discussões, pouco estendendo às discussões a respeito dos métodos até então utilizados nos artigos selecionados. Uma última limitação seria o enfoque genérico usado para identificar facilitadores à resiliência, não atrelando estes a elementos à montante ou à jusante da cadeia, ou ainda a uma função de negócio da empresa. Esta última limitação será solucionada a partir de um estudo empírico subsequente, que caracterizará facilitadores e sua interação com a função logística de indústrias.

Considerando tais limitações, diversas oportunidades futuras de pesquisas podem ser observadas, especialmente no contexto brasileiro em que poucos estudos sobre a temática foram encontrados - entre eles, Graeml e Peinado (2004, 2014), Pereira, Christopher e Silva (2014), Pereira e Silva (2015), Bradaschia (2015) 
e Scavarda et al. (2015). A primeira delas seria a avaliação dos facilitadores identificados por meio de um estudo empírico, de forma a ampliar as discussões a respeito dos agrupamentos de facilitadores, e como esses podem gerar resiliência na cadeia de suprimentos. Diante dessa oportunidade, a aplicação de um método misto para validar tais facilitadores, por meio de dados qualitativos e quantitativos, parece ser uma oportunidade relevante de validação dos dados e/ou complementação dos mesmos. Esta pesquisa deveria ainda considerar a relevância de cada facilitador para os diferentes tipos de ruptura.

Como uma segunda oportunidade, destacam-se estudos sob uma perspectiva qualitativa, em que estudos de caso podem considerar setores considerados altamente dinâmicos, tais como os setores de Fast-Fashion, o tecnológico e o agroindustrial. Nesse contexto, será possível identificar novas práticas e insights a respeito da criação de resiliência. Outra oportunidade de pesquisa está em desenvolver modelos teóricos que comparem as influências dos facilitadores identificados para lidar com diferentes tipos de rupturas.

Graeml e Peinado (2014) encontraram, em seu estudo, algumas distinções entre a realidade brasileira e a americana. Dentro desse contexto de facilitadores, é possível analisar perspectivas do que seriam fatores críticos à resiliência no contexto brasileiro e no contexto americano (por exemplo). Estudos que se utilizem de métodos mistos poderiam ainda contribuir com a temática, partindo da observação qualitativa dos facilitadores envolvidos com cada tipo de ruptura em algumas empresas, discutindo e validando-os.

\section{AGRADECIMENTOS}

Os autores agradecem à capes pelo apoio na publicação e na divulgação deste trabalho.

\section{REFERÊNCIAS}

ALMEIDA, F. Sete dias de bloqueios em rodovias provocam prejuízos para empresas. G1, 2015. Disponível em: <http://g1.globo.com/jornal-hoje/noticia/2015/02/sete-dias-debloqueios-em-rodovias-provocam-prejuizos-para-empresas.html>. Acesso em: 19/5/2015.

AMBULKAR, S.; BLACKHURST, J.; GRAWE, S. Firm ' s resilience to supply chain disruptions : Scale development and empirical examination. Journal of Operations Management, v. 33-34, p. 111-122, 2015. http://dx.doi.org/10.1016/j.jom.2014.11.002

BADGER, D.; NURSTEN, J.; WILLIAMS, P.; WOODWARD, M. Should All Literature Reviews be Systematic? Evaluation \& Research in Education, v. 14, n. 3-4, p. 220 230, 2010. http://dx.doi.org/10.1080/09500790008666974

BARDIN, L. Análise de Conteudo. 70th ed. 2008.

BARRETO, F.; AMARAL, D. C. Análise das recomendações para uso de escalas na Revista Produção Online, Florianópolis, SC, v. 16, n. 3, p. 916-946, jul./set. 2016. 
aplicação da Engenharia Kansei.In: Anais Congresso Brasileiro de Gestão de Desenvolvimento de Produto.p.1-11, 2013. Natal.

BAUER, M. W.; GASKELL, G. Pesquisa qualitativa com texto, imagem e som: um manual prático. Petrópolis: Vozes, 2003.

BLACKHURST, J.; CRAIGHEAD, C. W.; ELKINS, D.; HANDFIELD, R. B. An empirically derived agenda of critical research issues for managing supply-chain disruptions. International Journal of Production Research, v. 43, n. 19, 2005. Disponível em: <http://www.tandfonline.com/doi/abs/10.1080/00207540500151549>. Acesso em: $7 / 5 / 2014$.

BLACKHURST, J.; DUNN, K. S.; CRAIGHEAD, C. W. An Empirically Derived Framework of Global Supply Resiliency. Journal of Business Logistics, v. 32, n. 4, p. 374-391, 2011. Disponível em: <http://doi.wiley.com/10.1111/j.0000-0000.2011.01032.x>. Acesso em: 13/5/2014.

BRADASCHIA, M. C. Capabilities formadoras da resiliência em cadeias de serviços: um estudo de caso em saúde, 2015. FUNDAÇÃO GETULIO VARGAS.

BRANDON-JONES, E.; SQUIRE, B.; AUTRY, C. W.; PETERSEN, K. J. A contingent resource-based perspective of supply chain resilience and robustness. Journal of Supply Chain Management, p. 55-73, 2014.

BRINGER, J. D. Using Computer-Assisted Qualitative Data Analysis Software to Develop a Grounded Theory Project. Field Methods, v. 18, n. 3, p. 245-266, 2006. Disponível em: <http://fmx.sagepub.com/cgi/doi/10.1177/1525822X06287602>. Acesso em: 20/4/2015.

BUENO-SOLANO, A.; CEDILLO-CAMPOS, M. G. Dynamic impact on global supply chains performance of disruptions propagation produced by terrorist acts.

Transportation research part E, v. 61, p. 1-12, 2014. Elsevier Ltd. Disponível em: <http://dx.doi.org/10.1016/j.tre.2013.09.005>. Acesso em: 20/1/2015.

BURNARD, K.; BHAMRA, R. Organisational resilience: development of a conceptual framework for organisational responses. International Journal of Production

Research, v. 49, n. 18, p. 5581-5599, 2011. Disponível em:

<http://www.tandfonline.com/doi/abs/10.1080/00207543.2011.563827>. Acesso em: $10 / 7 / 2014$.

CARVALHO, H.; BARROSO, A. P.; MACHADO, V. H.; AZEVEDO, S.; CRUZMACHADO, V. Supply chain redesign for resilience using simulation. Computers \& Industrial Engineering, v. 62, n. 1, p. 329-341, 2012. Elsevier Ltd. Disponível em: <http://linkinghub.elsevier.com/retrieve/pii/S0360835211002907>. Acesso em: 10/7/2014.

CHRISTOPHER, M.; PECK, H. Building The Resilient Supply Chain. International Journal of Logistics Management, v. 15, n. 2, p. 1-13, 2004.

http://dx.doi.org/10.1108/09574090410700275

COLICCHIA, C.; STROZZI, F. Supply chain risk management: a new methodology for a systematic literature review. Supply Chain Management: An International Journal, v. 17, n. 4, p. 403-418, 2012. Disponível em:

<http://www.emeraldinsight.com/10.1108/13598541211246558>. Acesso em: 26/3/2014. 
CONFORTO, E. C.; AMARAL, D. C.; SILVA, S. L. Roteiro para revisão bibliográfica sistemática : aplicação no desenvolvimento de produtos e gerenciamento de projetos. In: Anais Congresso Brasileiro de Gestão de Desenvolvimento de Produto. v. 8, p.12, 2011. Porto Alegre.

CRAIGHEAD, C. W.; BLACKHURST, J.; RUNGTUSANATHAM, M. J.; HANDFIELD, R. B. The Severity of Supply Chain Disruptions : Design Characteristics and Mitigation Capabilities. Decision Sciences, v. 38, n. 1, p. 131-156, 2007. http://dx.doi.org/10.1111/j.1540-5915.2007.00151.x

DEMMER, W. A.; VICKERY, S. K.; CALANTONE, R. Engendering resilience in smalland medium-sized enterprises ( SMEs ): a case study of Demmer Corporation.

International Journal of Production Research, v. 49, p. 37-41, 2011. http://dx.doi.org/10.1080/00207543.2011.563903

DENYER, D.; TRANFIELD, D. Producing a Systematic Review. In: D. A. Buchanan; A. Bryman (Eds.); The SAGE Handbook of Organizational Research Methods. Sage ed., p.671-689, 2009. Londres: SAGE.

GIBBS, G. Análise de dados qualitativos. Porto Alegre: Bookman, 2009.

GOLGECI, I.; PONOMAROV, S. Y. Does firm innovativeness enable effective responses to supply chain disruptions? An empirical study. Supply Chain Management: An International Journal, v. 18, n. 6, p. 604-617, 2013. Disponível em: $<$ http://www.scopus.com/inward/record.url?eid=2-s2.084886008460\&partnerID=tZOtx3y1>. Acesso em: 3/6/2014.

GONG, J.; MITCHELL, J. E.; KRISHNAMURTHY, A.; WALLACE, W. A. An interdependent layered network model for a resilient supply chain. Omega, v. 46, p. 104116, 2014. Elsevier. Disponível em:

<http://linkinghub.elsevier.com/retrieve/pii/S0305048313000856>. Acesso em: 22/7/2014.

HEARNSHAW, E. J. S.; WILSON, M. M. J. A complex network approach to supply chain network theory. International Journal of Operations \& Production Management, $v$. 33, n. 4, p. 442-469, 2013. Disponível em: <http://www.emeraldinsight.com/10.1108/01443571311307343>. Acesso em: 13/7/2014.

HUTCHISON, A. J.; JOHNSTON, L. H.; BRECKON, J. D. Using QSR-NVivo to facilitate the development of a grounded theory project: an account of a worked example.

International Journal of Social Research Methodology, v. 13, n. 4, p. 283-302, 2010. Disponível em: <http://www.tandfonline.com/doi/abs/10.1080/13645570902996301>. Acesso em: 20/4/2015.

INSTITUTO DE LOGÍSTICA E SUPPLY CHAIN - ILOS. Manifestação afeta logística e já para fábricas pelo país. , 10. Jan. 2013. Disponível em:

$<$ http://www.ilos.com.br/clipping/index.php?option=com_content\&task=view\&id=7009\&lte >. Acesso em: 10/3/2014.

JESSON, J. K.; MATHESON, L.; LACEY, F. M. The Systematic Review. In: (Eds.); Doing Your Literature Review. p.103-127, 2011. Londres.

JOHNSON, N.; ELLIOTT, D.; DRAKE, P. Exploring the role of social capital in facilitating supply chain resilience. Supply Chain Management: An International Journal, v. 18, n. 3, p. 324-336, 2013. Disponível em: <http://www.emeraldinsight.com/10.1108/SCM06-2012-0203>. Acesso em: 31/5/2014.

Revista Produção Online, Florianópolis, SC, v. 16, n. 3, p. 916-946, jul./set. 2016. 
JOHNSTON, L. Software and Method: Reflections on Teaching and Using QSR NVivo in Doctoral Research. International Journal of Social Research Methodology, v. 9, n. 5, p. 379-391, 2006. Disponível em:

<http://www.tandfonline.com/doi/abs/10.1080/13645570600659433>. Acesso em:

18/5/2015.

JÜTTNER, U.; MAKLAN, S. Supply chain resilience in the global financial crisis: an empirical study. Supply Chain Management: An International Journal, v. 16, n. 4, p. 246-259, 2011. Disponível em:

<http://www.emeraldinsight.com/10.1108/13598541111139062>. Acesso em: 18/7/2014.

KAMALAHMADI, M.; MELLAT, M. A review of the literature on the principles of enterprise and supply chain resilience: Major findings and directions for future research. Intern.

Journal of Production Economics, v. 171, p. 116-133, 2016.

KHAN, O.; CHRISTOPHER, M.; CREAZZA, A. Aligning product design with the supply chain: a case study. Supply Chain Management: An International Journal, v. 17, n. 3 , p. 323-336, 2012. Disponível em:

<http://www.emeraldinsight.com/10.1108/13598541211227144>. Acesso em: 2/4/2014.

KHAN, O.; ESTAY, D. A. S. Supply Chain Cyber-Resilience: Creating an Agenda for Future Research. Technology Innovation Management Review, p. 6-12, 2015.

Disponível em:

$<$ http://timreview.ca/sites/default/files/article_PDF/Khan_SepúlvedaEstay_TIMReview_Ap ril2015.pdf>. Acesso em: 13/7/2015.

KIM, Y.; CHEN, Y.-S.; LINDERMAN, K. Supply Network Disruption and Resilience: A Network Structural Perspective. Journal of Operations Management, v. 33-34, p. 4359, 2014. Elsevier B.V. Disponível em:

<http://linkinghub.elsevier.com/retrieve/pii/S0272696314000746>. Acesso em:

28/10/2014.

KRIPPENDORFF, K. Content Analysis: an introduction to its methodology. 3. ed. Los Angeles: SAGE Publications, 2013.

LUKAS, B. A.; FERRELL, O. C. The effect of market orientation on product innovation. Journal of the academy of marketing science, v. 28, p. 239-247, 1997.

http://dx.doi.org/10.1177/0092070300282005

MCCORMACK, K. P.; BRONZO, M.; OLIVEIRA, M.P.V. Uma abordagem probabilística para a avaliação de riscos em cadeias de suprimento. Revista Produção Online, v. 10, n. 3, p. 577-598, 2010. http://dx.doi.org/10.14488/1676-1901.v10i3.294

MELO, L. Roubo de dados pode levar Target a pagar US\$ 10 milhões. Disponível em: <http://exame.abril.com.br/negocios/noticias/roubo-de-dados-pode-levar-target-a-pagarus-10-milhoes>. Acesso em: 14/4/2015.

WALLACE, M.; WRAY, A. Critical reading and writing for postgraduates. Sage publications, 2011.

OLIVEIRA, L. G.; FREITAS, D. C.; BATALHA, M. O.; ALCÂNTARA, R. L. C.

Gerenciamento de riscos na cadeia agroindustrial de frango: análise da perspectiva dos avicultores em Ubá, Minas Gerais. Revista Produção Online, v. 15, n. 4, p. 1305-1325, 2015. http://dx.doi.org/10.14488/1676-1901.v15i4.1908

Revista Produção Online, Florianópolis, SC, v. 16, n. 3, p. 916-946, jul./set. 2016. 
PEREIRA, C. R.; CHRISTOPHER, M.; SILVA, A. L. Achieving supply chain resilience: the role of procurement. Supply Chain Management: An International Journal, v. 19, n. 5/6, p. $626-642,2014$. http://dx.doi.org/10.1108/SCM-09-2013-0346

PEREIRA, C. R.; SILVA, A. L. Key Organisational Factors to Building Supply Chain Resilience: a Multiple Case Study of Buyers and Suppliers. Journal of Operations and Supply Chain Management, 8(2), 77-95, 2015.

http://dx.doi.org/10.12660/joscmv8n2p77-95

PETTIT, T. J.; FIKSEL, J.; CROXTON, K. L. Ensuring Supply Chain Resilience:

Development of a conceptual framework. Journal of Business Logistics, v. 31, n. 1, p. 1-22, 2010. http://dx.doi.org/10.1002/j.2158-1592.2010.tb00125.x

PONOMAROV, S. Y.; HOLCOMB, M. C. Understanding the concept of supply chain resilience. The International Journal of Logistics Management, v. 20, n. 1, p. 124 143, 2009. Disponível em:

<http://www.emeraldinsight.com/10.1108/09574090910954873>. Acesso em: 20/3/2014.

PUPO, F.; LAGUNA, E.; BRUNO, L. Manifestação afeta logística e já para fábricas pelo país. Valor Econômico, 2013. Disponível em:

<http://www.valor.com.br/empresas/3183366/manifestacao-afeta-logistica-e-ja-parafabricas-pelo-pais\#ixzz2z3GYBW7o>. Acesso em: 12/8/2015.

QDA MINER. Qualitative data analysis software. Disponível em:

$<$ http://provalisresearch.com/products/qualitative-data-analysis-software/qda-minerfeatures/>. Acesso em: 2/8/2015.

RICE, J. B.; CANIATO, F. Building a Secure And Resilient Supply Network. Supply Chain Management Review. p. 22-30, 2003. Disponível em:

$<$ http://web.mit.edu/scresponse/repository/Rice_SCResp_Article_SCMR.pdf>. Acesso em: $14 / 8 / 2014$.

ROBREDO, J.; CUNHA, M. B. DA. Aplicação de técnicas infométricas para identificar a abrangência do léxico básico que caracteriza os processos de indexação e recuperação da informação. Ciência da Informação, v. 27, n. 1, p. 11-27, 1998.

http://dx.doi.org/10.1590/S0100-19651998000100003

SCAVARDA, L. F.; CERYNO, P. SANTOS; PIRES, S.; KLINGEBIEL, K. Supply chain resilience analysis : a brazilian automotive case. RAE - Revista de Administração de Empresas, v. 55, p. 304-313, 2015.

SCHMITT, A. J.; SINGH, M. A quantitative analysis of disruption risk in a multi-echelon supply chain. International Journal of Production Economics, v. 139, n. 1, p. 22-32, 2012. Elsevier. Disponível em:

<http://linkinghub.elsevier.com/retrieve/pii/S0925527312000059>. Acesso em: 30/6/2014.

SCHOLTEN, K.; SCOTT, P. S.; FYNES, B. Mitigation processes - antecedents for building supply chain resilience. Supply Chain Management: An International Journal, v. 19, n. 2, p. 211-228, 2014. Disponível em:

<http://www.emeraldinsight.com/10.1108/SCM-06-2013-0191>. Acesso em: 18/7/2014.

SHEFFI, Y.; RICE, J. B. R. J. A Supply Chain View of the Resilient Enterprise. MITSloan Management Review, v. 47, n. 1, p. 41-49, 2005.

Revista Produção Online, Florianópolis, SC, v. 16, n. 3, p. 916-946, jul./set. 2016. 
SILVESTRE, B. S.. Sustainable Supply Chain Management in Emerging Economies: Environmental Turbulence, Institutional Voids and Sustainability Trajectories. International Journal of Production Economics, v. 167, p. 156-169, 2015. http://dx.doi.org/10.1016/j.ijpe.2015.05.025

STECKE, K. E., \& KUMAR, S. Sources of supply chain disruptions, factors that breed vulnerability, and mitigating strategies. Journal of Marketing Channels, v. 16, n. 3, p. 193-226, 2009. http://dx.doi.org/10.1080/10466690902932551

SVENSSON, G. The principle of balance between companies ' inventories and disturbances Empirical illustration and. International Journal of Physical Distribution \& Logistics Management, v. 33, n. 9, p. $765-784,2003$.

http://dx.doi.org/10.1108/09600030310503325

TANG, C. S. A Leading Journal of Supply Chain Management Robust strategies for mitigating supply chain disruptions. International Journal of Logistics Research and Applications: A Leading Journal of Supply Chain Management, v. 9, n. 1, p. 37-41, 2007.

THOMÉ, A. M. T.; SCAVARDA, L. F.; FERNANDEZ, N. S.; SCAVARDA, A. J. Sales and operations planning: A research synthesis. International Journal of Production Economics, v. 138, n. 1, p. 1-13, 2012. Disponível em:

<http://linkinghub.elsevier.com/retrieve/pii/S0925527311004907>. Acesso em: 2/5/2014.

THUN, J.-H.; HOENIG, D. An empirical analysis of supply chain risk management in the German automotive industry. International Journal of Production Economics, v. 131, n. 1, p. 242-249, 2011. Disponível em:

<http://linkinghub.elsevier.com/retrieve/pii/S0925527309003715>. Acesso em: 10/7/2014.

TRANFIELD, D.; DENYER, D.; SMART, P. Towards a Methodology for Developing Evidence-Informed Management Knowledge by Means of Systematic Review. British Journal of Management, v. 14, p. 207-222, 2003. http://dx.doi.org/10.1111/1467$\underline{8551.00375}$

VALOR ECONÔMICO. Greve de caminhoneiros entra no $2^{\circ}$ dia com bloqueio em rodovias gaúchas. , 2015. Disponível em:

<http://www.valor.com.br/brasil/4019856/greve-de-caminhoneiros-entra-no-2>. Acesso em: 19/5/2015.

VEGT, G. S. VAN DER; ESSENS, P.; WAHLSTRÖM, M.; GEORGE, G. Managing risk and resilience. Academy of Management Journal, v. 58, n. 4, p. $971-980,2015$. http://dx.doi.org/10.1080/08865655.2008.9695683.

WIELAND, A.; WALLENBURG, C. M. The influence of relational competencies on supply chain resilience: a relational view. International Journal of Physical Distribution \& Logistics Management, v. 43, n. 4, p. 300-320, 2013. Disponível em:

<http://www.emeraldinsight.com/10.1108/IJPDLM-08-2012-0243>. Acesso em: $30 / 7 / 2014$.

ZHANG, D.; DADKHAH, P.; EKWALL, D. How robustness and resilience support security business against antagonistic threats in transport network. Journal of Transportation

Security, v. 4, n. 3, p. 201-219, 2011. Disponível em:

<http://link.springer.com/10.1007/s12198-011-0067-2>. Acesso em: 19/8/2014.

Revista Produção Online, Florianópolis, SC, v. 16, n. 3, p. 916-946, jul./set. 2016. 
ZSIDISIN, G. A.; ELLRAM, L. M.; CARTER, J. R.; CAVINATO, J. L. An analysis of supply risk assessment techniques. International Journal of Physical Distribution \& Logistics Management, v. 34, n. 5, p. 397-413, 2004.

http://dx.doi.org/10.1108/09600030410545445

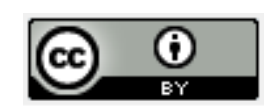

Artigo recebido em 13/11/2015 e aceito para publicação em 04/08/2016

DOI: http://dx.doi.org/ 10.14488/1676-1901.v16i3.2223 


\section{APÊNDICE A: Lista de Códigos, Grupos e Frequência de codificação}

\begin{tabular}{llcccc}
\hline \multicolumn{1}{c}{ Grupo } & \multicolumn{1}{c}{ Código } & Contagem & $\begin{array}{c}\text { \% de } \\
\text { Códigos }\end{array}$ & Casos & $\begin{array}{c}\text { \% de } \\
\text { Casos }\end{array}$ \\
\hline $\begin{array}{l}\text { Facilitadores a } \\
\text { resiliência }\end{array}$ & $\begin{array}{l}\text { Agilidade de reação a } \\
\text { rupturas }\end{array}$ & 94 & $8,40 \%$ & 22 & $61,10 \%$ \\
\hline $\begin{array}{l}\text { Facilitadores a } \\
\text { resiliência }\end{array}$ & Colaboração & 135 & $12,10 \%$ & 23 & $63,90 \%$ \\
\hline $\begin{array}{l}\text { Facilitadores a } \\
\text { resiliência }\end{array}$ & Comunicação & 79 & $7,10 \%$ & 20 & $55,60 \%$ \\
\hline $\begin{array}{l}\text { Facilitadores a } \\
\text { resiliência }\end{array}$ & $\begin{array}{l}\text { Estrutura da cadeia de } \\
\text { suprimentos }\end{array}$ & 55 & $4,90 \%$ & 16 & $44,40 \%$ \\
\hline $\begin{array}{l}\text { Facilitiadores a } \\
\text { resiliência }\end{array}$ & Flexibilidade & 202 & $18,10 \%$ & 30 & $83,30 \%$ \\
\hline $\begin{array}{l}\text { Facilitadores a } \\
\text { resiliência }\end{array}$ & Gestão de riscos & 121 & $10,90 \%$ & 24 & $66,70 \%$ \\
\hline $\begin{array}{l}\text { Facilitadores a } \\
\text { resiliência }\end{array}$ & $\begin{array}{l}\text { Gestão do } \\
\text { conhecimento }\end{array}$ & 41 & $3,70 \%$ & 15 & $41,70 \%$ \\
\hline $\begin{array}{l}\text { Facilitadores a } \\
\text { resiliência }\end{array}$ & Grupos Interfuncionais & 16 & $1,40 \%$ & 7 & $19,40 \%$ \\
\hline $\begin{array}{l}\text { Facilitadores a } \\
\text { resiliência }\end{array}$ & Redundância & 167 & $15,00 \%$ & 30 & $83,30 \%$ \\
\hline $\begin{array}{l}\text { Facilitadores a } \\
\text { resiliência }\end{array}$ & Saúde financeira & 11 & $1,00 \%$ & 5 & $13,90 \%$ \\
\hline $\begin{array}{l}\text { Facilitadores a } \\
\text { resiliência }\end{array}$ & Tecnologia & 31 & $2,80 \%$ & 18 & $50,00 \%$ \\
\hline $\begin{array}{l}\text { Facilitadores a } \\
\text { resiliência }\end{array}$ & Visibilidade & 161 & $14,50 \%$ & 29 & $80,60 \%$ \\
\hline
\end{tabular}

